\title{
RELAÇÕES INTERNACIONAIS: O MERCADO DE TRABALHO PARA O INTERNACIONALISTA NO BRASIL
}

\author{
Jorge Luiz Marques Schlichting ${ }^{1}$
}

Ingrid Barbosa Moreira ${ }^{2}$

Rafael Cordeiro Vilas Boas de Andrade ${ }^{3}$

Audren Marlei Azolin (orientadora) ${ }^{4}$

\begin{abstract}
Resumo
Neste século XXI as transformações ocorridas e as que estão ainda em curso, em grande medida devido à globalização, nos mostram a importância do internacionalista nos processos políticos e comerciais. A questão que move este comunicado consiste no seguinte: como se encontra o mercado de trabalho para o internacionalista no Brasil? A partir deste questionamento mais amplo, questiona-se também quais são as áreas de atuação do internacionalista no Brasil? O objetivo geral é mapear o mercado de trabalho para o internacionalista no Brasil. O que nos leva a mapear as atividades, funções, áreas de atuação, perfil profissional etc. Por sua vez, os objetivos específicos são: 1) Identificar e analisar o mercado de trabalho para o internacionalista na perspectiva de cursos de bacharelado em Relações Internacionais e 2) classificar o mercado de trabalho para o internacionalista no Brasil, identificando as diferentes áreas de atuação. Nossas fontes de pesquisa foram os dados do Ministério da Educação (E-mec) e os sites dos cursos de relações internacionais analisados. A metodologia utilizada é exploratória, uma vez que não foi identificada uma literatura consolidada que trate do assunto, além de poucos estudos sobre o tema. A estratégia metodológica utilizada é quantitativa e qualitativa, a partir da Análise de Conteúdo que, enquanto técnica, nos permite classificar o mercado de trabalho para o internacionalista em diversas categorias relativas às áreas de atuação e às atividades do internacionalista, apresentadas nas ofertas de emprego e estágio. Quantitativamente identificou-se, dentro do universo analisado a proeminência da modalidade presencial, de IES com natureza privada, concentração dos cursos no Sudeste brasileiro e que os sites fazem mais referência a atividades do espaço de atuação privado. Qualitativamente a análise, nos trouxe que há um significativo avanço dentro do espaço privado, da área afeta às relações governamentais/institucionais como atividade desenvolvida pelo internacionalista.
\end{abstract}

Palavras-Chave: Relações Internacionais; Mercado de Trabalho; Áreas de Atuação; Atividades Profissionais; Profissionalização.

\section{INTRODUÇÃO}

O mundo do trabalho vem se modificando de forma constante e muito célere, mais especificamente no século XXI. E com certeza essa realidade se aplica ao mercado de trabalho para

\footnotetext{
${ }^{1}$ Centro Universitário Internacional Uninter, jlmschlichting16@gmail.com, ORCID 0000-0002-5337-8504.

${ }^{2}$ Centro Universitário Internacional Uninter, ingridbmoreira@hotmail.com, ORCID 0000-0002-6143-5804.

${ }^{3}$ Centro Universitário Internacional Uninter, rafinhavilasboas11 @ gmail.com, ORCID 0000-0001-9576-3841.

${ }^{4}$ Centro Universitário Internacional Uninter, audren.a@uninter.com, ORCID 0000-0003-2523-8798.
} 
o internacionalista. Um dos fatores que afetou o mundo do trabalho foi a globalização. As transformações já ocorridas e as que estão ainda em curso têm nos mostrado a importância do internacionalista nos processos políticos e comerciais. Dito isto, o objeto de pesquisa aqui proposto consiste no mercado de trabalho para o internacionalista no Brasil. É importante ressaltar que se trata de pesquisa em andamento, em fase inicial, desenvolvida por graduandos do Curso de Relações Internacionais do Centro Universitário Internacional Uninter, em programa de iniciação científica. Enquanto projeto de iniciação científica quer 1) identificar e analisar o mercado de trabalho para o internacionalista na perspectiva de cursos de bacharelado em Relações Internacionais em funcionamento no Brasil (PPC - perfil do egresso, área de atuação, atividades etc.); 2) identificar e analisar o mercado de trabalho para o internacionalista na perspectiva do mercado de trabalho brasileiro (vagas de emprego e estágio); bem como, classificar o mercado de trabalho para o internacionalista no Brasil, identificando as diferentes áreas de atuação.

O projeto será desenvolvido durante o ano de 2020. Nesta fase da pesquisa, estamos identificando e analisando o mercado de trabalho para o internacionalista na perspectiva dos cursos de bacharelado em Relações Internacionais em funcionamento no Brasil que obtiveram nota 5, foco deste trabalho. A identificação e análise do mercado de trabalho na perspectiva das vagas ofertadas no Brasil de emprego e estágio para o internacionalista é objetivo para a próxima fase. De posse dos dados sobre o mercado na perspectiva dos cursos e das vagas de emprego e estágio será possível então, classificar o mercado de trabalho para o internacionalista no Brasil, identificando as diferentes áreas de atuação.

Dito isto, podemos colocar que as fontes de pesquisa são os sites dos Cursos de Bacharelado em Relações Internacionais (com nota 5) e do Ministério da Educação (MEC), mais especificamente a base de dados do E-mec,

O problema de pesquisa é: quais são as áreas de atuação do internacionalista no Brasil? Ter a clareza sobre as diferentes áreas do mercado de trabalho é relevante para construção da carreira profissional do internacionalista. Desta forma, o problema de pesquisa ora formulado, torna-se importante elemento para formação dos alunos e alunas ainda na graduação.

Embora importante, não é suficiente responder quais são as áreas de atuação. Assim, do problema de pesquisa principal deriva outra questão: quais as principais atividades deste profissional no mercado de trabalho?

O objetivo geral deste comunicado é o de mapear o mercado de trabalho para o internacionalista no Brasil. Isso quer dizer mapear as atividades, funções, áreas de atuação, perfil profissional etc. Por 
sua vez, os objetivos específicos são: 1) Identificar e analisar o mercado de trabalho para o internacionalista na perspectiva de cursos de bacharelado em Relações Internacionais em funcionamento no Brasil (PPC - perfil do egresso, área de atuação, atividades etc.); 2) Classificar o mercado de trabalho para o internacionalista no Brasil. Classificar aqui se entende por identificar as diferentes áreas de atuação.

Esta pesquisa encontra sua justificativa e motivação nos questionamentos de muitos alunos e alunas do Curso de Bacharelado em Relações Internacionais do Centro Universitário Internacional UNINTER sobre onde trabalhar na esfera privada, que atividades desenvolve o internacionalista nesta esfera, quais são as áreas de atuação no mercado de trabalho para o profissional de relações internacionais no Brasil, dentre tantos outros questionamentos. Outro aspecto que justifica a pesquisa é o fato de que nos deparamos com praticamente uma ausência de pesquisas que tratam dessa temática, o que reforça a pertinência desta pesquisa.

Para esta pesquisa a expressão empregabilidade assume importância central. Assim, é necessário entender a definição de empregabilidade. De acordo com Gustavo Borges de Azevedo et. al.,

Empregabilidade pode ser entendida como a capacidade de um indivíduo se manter no mercado de trabalho, onde ele se mostra capaz de competir com outros indivíduos por um emprego. [...]. Observa-se que é uma preocupação a questão da empregabilidade, pois, envolve a visibilidade do país, sua economia e a qualidade de vida da população. Com tudo, a empregabilidade pode ser percebida como um conjunto de habilidades de um indivíduo que são necessárias para que ele venha garantir sua vaga de trabalho e se manter no emprego (Borges et. al., 2019, p. 6).

A empregabilidade é uma definição que foca no indivíduo, isto é, sua qualidade para o exercício de atividades e funções no mundo do trabalho. No entanto, notadamente a empregabilidade transcende a esfera do indivíduo, sendo importante para o país como um todo. De acordo com Hedal e Rocha (2011 Apud Borges et. al., 2019, p. 6) “A palavra 'empregabilidade' ocupa posição de destaque na academia, no mundo empresarial e nas discussões sobre políticas públicas, no Brasil e em outros países".

A empregabilidade é um conceito em movimento que mobiliza a ação do indivíduo. Segundo Ana Luisa da Costa Lemos e Daniel Arbaiza Rodriguez,

Conceito em construção, o termo empregabilidade atualiza as condições de mobilização e de qualificação da força de trabalho, até então vigentes. Sob a égide da empregabilidade, cabe ao trabalhador mostrar-se atraente aos olhos do empregador e comprometido permanentemente com a melhoria de sua qualificação profissional, que deixa de ser somente uma atividade concentrada em um período da vida do trabalhador, para tornar-se uma exigência constante de atualização das capacidades adquiridas, um movimento individual em 
direção à conquista de novas habilidades e disposições. Subjacente a esse entendimento está a noção de que uma nova atitude frente ao trabalho é esperada e essa atitude vem modificando a relação tradicional do trabalhador com a esfera produtiva (Lemos; Rodriguez, 2008, p. 1).

Quando se trata de empregabilidade, o debate atual centra-se nas causas da crise do emprego. Lemos e Pinto (2008) apresentaram três vertentes que apontam causas distintas. A primeira vertente destaca, a partir da ideia de que se produza mais com menos mão de obra, que são os grandes avanços tecnológicos como sendo a principal causa pela diminuição drástica da oferta de emprego.

Outra vertente entende ser a globalização econômica a responsável pela diminuição de emprego, em especial em países periféricos. E por fim, a que entende que o despreparo, isto é, a falta de qualificação dos trabalhadores como causadora da crise do emprego (Lemos; Pinto, 2008, p. 2).

Aqui surge uma questão relevante para este artigo, a saber: a globalização enquanto fator de gerador da crise de emprego. Isso porque,

Com o aumento das comunicações entre diferentes lugares do mundo e o crescimento das diversas questões mundiais - meio ambiente, terrorismo, direitos humanos, crescente globalização - tornou-se essencial à entrada de profissionais especializados, que possam lidar e analisar essas situações. Assim, encontramos os profissionais de Relações Internacionais (RI) (Zago; Silveira, 2018, p. 1).

Nota-se que a globalização fonte geradora da crise do trabalho, é também fonte geradora do mercado de trabalho para o internacionalista. Frente a este cenário, o internacionalista tem que se mobilizar para buscar a empregabilidade ofertada pela própria globalização. Estamos, assim, diante de um paradoxo que favorece o internacionalista, tornando a empregabilidade ainda mais crucial para este profissional.

A metodologia utilizada é exploratória, uma vez que não foi identificada uma literatura consolidada que trate do assunto, além de poucos estudos sobre o tema. A estratégia metodológica utilizada é qualitativa e quantitativa. A Análise de Conteúdo surge enquanto opção metodológica para combinar as estratégias metodológicas qualitativa e quantitativa.

A Análise de Conteúdo, enquanto instrumental analítico, permite-nos classificar o mercado de trabalho para o internacionalista. De acordo com Bardin,

A técnica consiste em classificar os diferentes elementos nas diversas gavetas segundo critérios susceptíveis de fazer surgir um sentido capaz de introduzir uma certa ordem na confusão inicial. É evidente que tudo depende, no momento da escolha dos critérios de classificação, daquilo que se procura ou que se esperar encontrar (Bardin, 1994, p. 37). 
A Análise de Conteúdo metodologicamente permite que textos (analisados qualitativamente) sejam transformados em dados quantitativos. Como nos ensinou Bardin (1994, p. 38), "A intenção da análise de conteúdo é a inferência de conhecimentos relativos às condições de produção (ou, eventualmente, de recepção), inferência esta que recorre a indicadores (quantitativos ou não)".

Ainda sobre a Análise de Conteúdo, mais especificamente a descrita por Laurence Bardin em seu livro Análise de Conteúdo (2011), segundo a autora, esse método é composto por três etapas: préanálise, a exploração do material e o tratamento dos resultados obtidos e a interpretação.

A definição sobre a análise de conteúdo de Bernard Berelson é amplamente utilizada, "uma técnica de investigação que através de uma descrição objetiva, sistemática e quantitativa do conteúdo manifesto das comunicações tem por finalidade e interpretação destas mesmas comunicações" (apud Bardin, 2011, p. 42).

Neste estágio da pesquisa, com o foco na perspectiva dos cursos, foram selecionados os cursos de Relações Internacionais com o conceito 5. O Ministério da Educação defende que "cursos com conceito 5 serão cursos de excelência, devendo ser vistos como referência pelos demais".

Utilizando as etapas elencadas por Bardin, como primeiro passo foram identificados os cursos de conceito 5 através do site do e-MEC, gerenciado pelo Ministério da Educação, foi utilizada consulta avançada de forma que os resultados fossem apenas os nossos objetos de pesquisa, as Instituições de Ensino Superior (IES) selecionadas foram catalogadas em uma planilha do Excel.

Os textos foram coletados em páginas dos cursos de Relações Internacionais nos sites das IES previamente, em seguida os conteúdos encontrados foram transcritos para uma ficha e posteriormente analisados qualitativamente, e os dados identificados durante estas análises foram inseridos em uma planilha do Excel para avaliação quantitativa. Buscando auxiliar as análises foi feita uma planilha identificando e detalhando os espaços de atuação, as atividades desenvolvidas e cargos e/ou funções dentro de cada área, esses dados foram categorizados a partir das descrições do artigo da Zago e do Silveria (2017).

A ficha qualitativa foi utilizada para identificar as citações sobre os cargos, atividades e as seguintes áreas de atuação: pública, privada; terceiro setor; organizações internacionais e academia (Zago; Silveria, 2017). Essas áreas foram selecionadas pois o formando em relações internacionais,

Podem voltar-se para área empresarial, atuando em empresas direcionadas para o comércio exterior, ou dirigir-se para o campo de pesquisa e academia. Ainda pode optar pela área que se encontram os concursos públicos, ou também pelas Organizações Não Governamentais (ONGs) e pelas Organizações Intergovernamentais, além de novas áreas que continuam sendo descobertas. (Zago; Silveira, 2017, p.4). 
As áreas mencionadas anteriormente também foram utilizadas na planilha qualitativa para identificar a quantidade de menções para tais espaços de atuações, além de buscar identificar e catalogar a Unidade Federativa, Região, Natureza da IES, Situação. Também através da planilha foram gerados gráficos para facilitar a compreensão e identificação de paralelos e diferenças.

\section{O MERCADO DE TRABALHO PARA O INTERNACIONALISTA NA PERSPECTIVA DOS CURSOS DE BACHARELADO EM RELAÇÕES INTERNACIONAIS}

$\mathrm{Na}$ base de dados do E-mec encontramos mais de duas centenas de cursos de bacharelado em Relações Internacionais, 209 para sermos mais exatos. Dentre eles, 40 obtiveram conceito do curso nota 5 . O projeto de pesquisa, em sua continuidade, pretende analisar todos os cursos, neste momento o universo analisado restringe-se aos cursos com conceito 5, pois sobre estes também pudemos analisar o conteúdo sobre mercado de trabalho contido nos sites.

Esta seção está dividida em dois momentos. O primeiro, de característica quantitativa, tem como foco a descrição e análise dos principais aspectos do universo analisado, como a modalidade, unidade da federação e região onde estes cursos estão sediados, natureza da IES (dados do E-mec) e sua relação com os espaços de atuação (público, privado, terceiro setor, organizações internacionais, acadêmico). Os dados sobre espaço de atuação foram coletados dos sites dos cursos analisados.

O segundo momento, mais qualitativo, busca identificar, a partir das análises dos sites dos cursos, os cargos, as atividades e áreas de atuação (pública, privada; terceiro setor; organizações internacionais e academia) referenciados nestes sites, propondo a discussão e o levantamento dos pontos relevantes. Tanto os dados no E-mec, como nos sites dos cursos analisados foram coletados entre os meses de maio e junho do presente ano.

\subsection{O PERFIL DOS CURSOS DE RELAÇÕES INTERNACIONAIS}

A partir dos dados coletados, vemos, a partir do gráfico 1, que dentre os cursos analisados, 95\% são cursos na modalidade presencial e 5\% na modalidade a distância. 


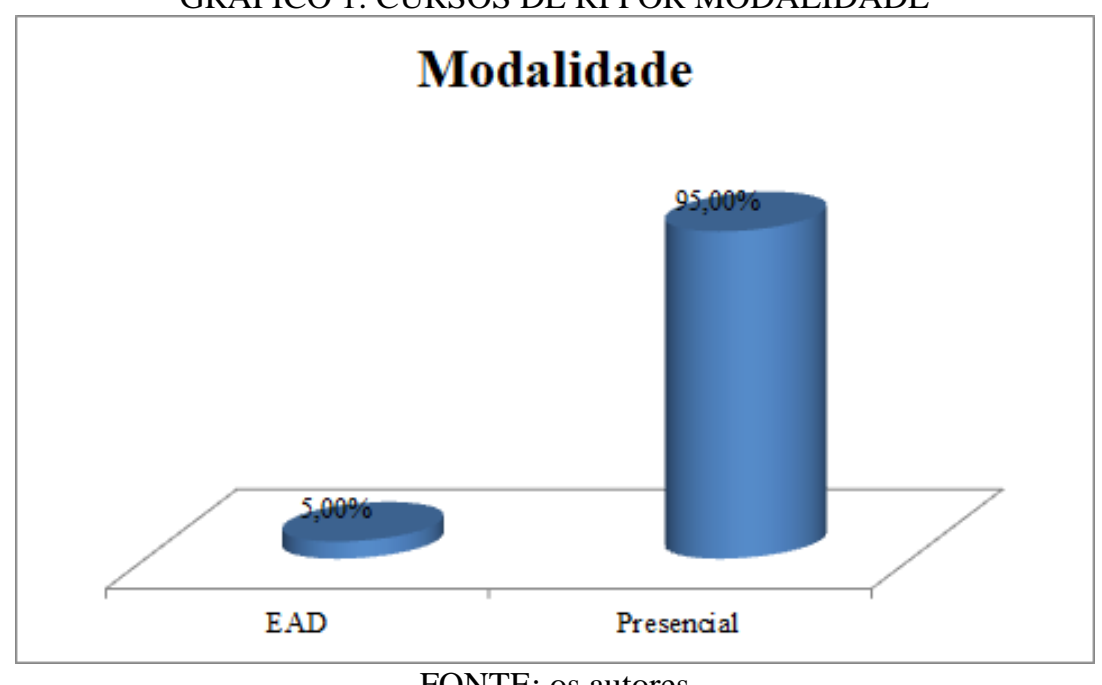

FONTE: os autores

No gráfico 2, os dados nos colocam frente à situação da natureza das instituições de ensino nos cursos analisados. Vemos que independente da modalidade, $75 \%$ dos cursos com conceito 5 de Relações Internacionais são de natureza privada, 22,5\% pública e 2,5\% comunitária. Assim, os cursos analisados estão concentrados em instituições privadas.

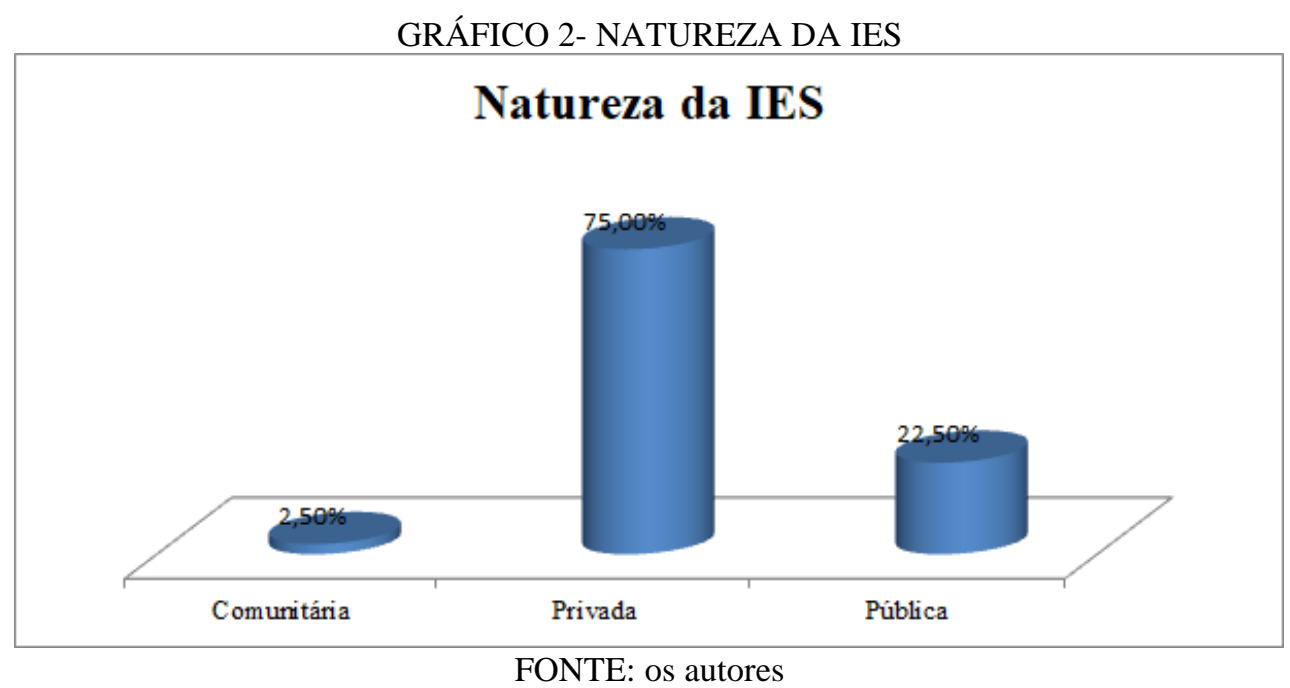

Sobre a concentração dos cursos analisados entre as unidades da federação, vemos no gráfico 3 que 27,5 \% dos cursos se concentram em São Paulo, 15\% no Rio de Janeiro e a mesma quantidade encontramos no Rio Grande do Sul, $10 \%$ estão em Minas Gerais, e 5\% nos estados do Paraná, Santa Catarina, Bahia e Distrito Federal. 


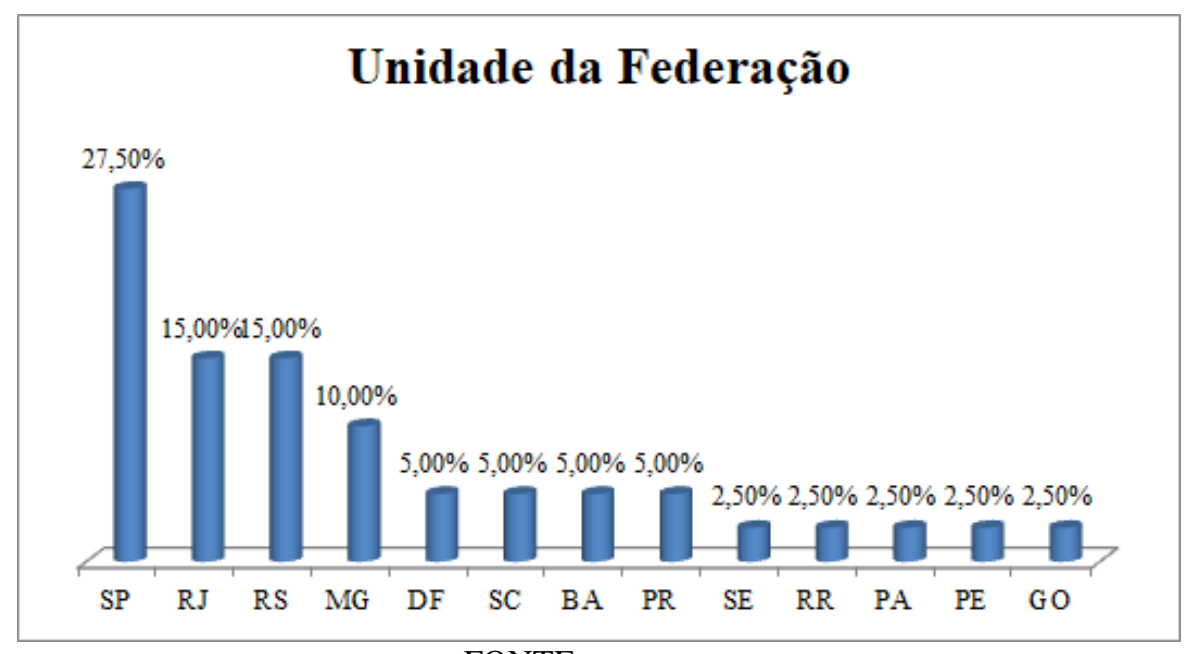

FONTE: os autores

No gráfico 4 temos que 50\% dos cursos objeto da análise se concentram na Região Sudeste e $25 \%$ na Região Sul. O que nos revela a concentração de $75 \%$ dos cursos oferecidos entre as Regiões Sudeste e Sul. Temos apenas 5\% de cursos na Região Norte do país, $10 \%$ nas Regiões Nordeste e Centro Oeste.

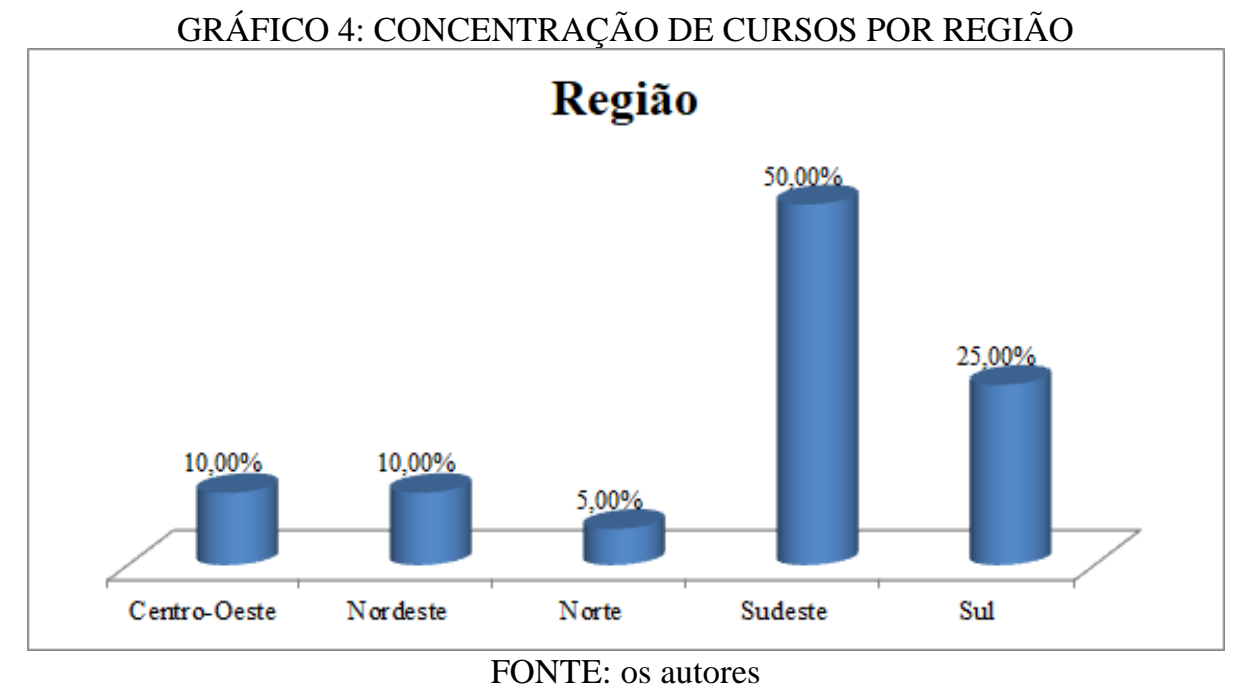

Quando olhamos para a situação dos cursos analisados, os dados nos mostram que 92,5\% estão em atividade, $7,5 \%$ em extinção. 
GRÁFICO 5: SITUAÇÃO

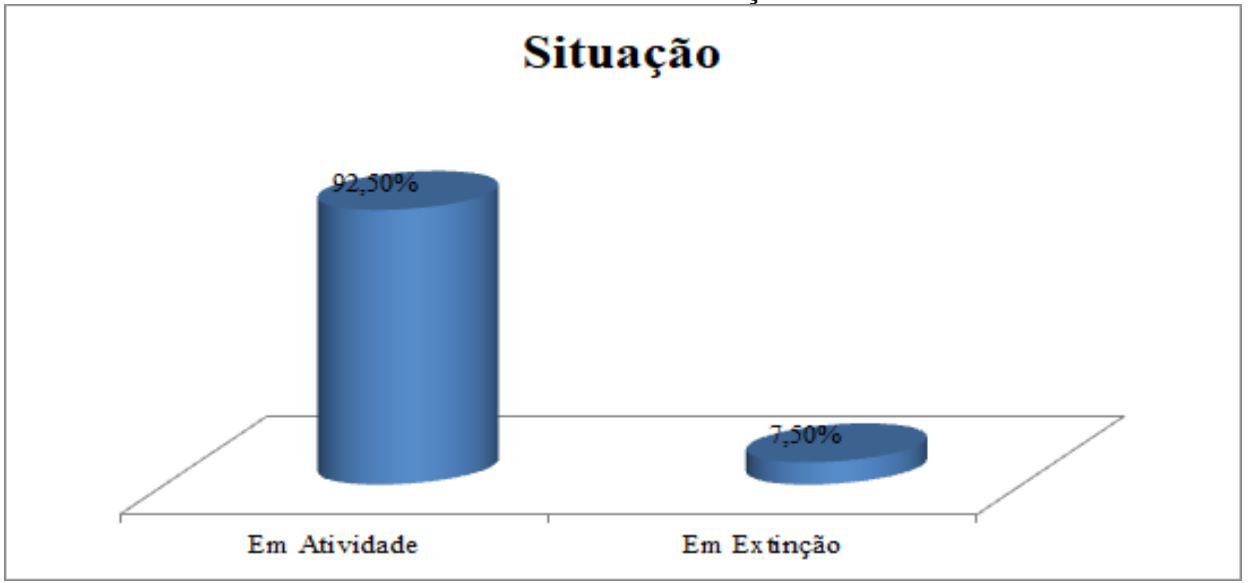

FONTE: os autores

A próxima sequência de gráficos focará nos espaços de atuação: privado, público, organizações internacionais, terceiro setor e acadêmico. Estas informações relacionadas aos espaços de atuação, foram coletadas nos sites dos cursos analisados e a classificação (privado, público, organizações internacionais, terceiro setor e acadêmico) de Zago e Silveira.

No gráfico 6 os dados revelam que o conjunto dos cursos de relações internacionais analisados (sem considerar a natureza da IES) fazem maior referência ao setor privado.

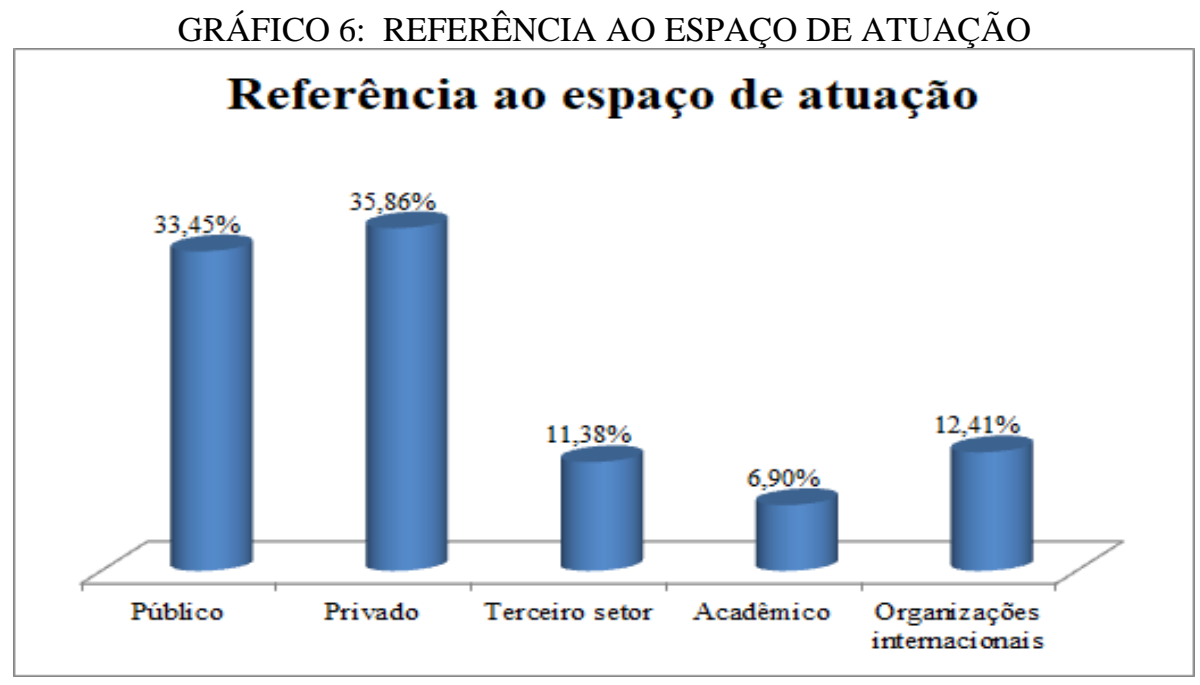

FONTE: os autores

Podemos ver no gráfico acima uma pequena discrepância entre a referência ao espaço público e privado. No entanto, ao sofisticarmos melhor a análise, o gráfico 7 revela que são as IES de natureza privada são as que fazem mais referências ao espaço privado.

Considerando o total das IES analisadas, quando fazem referências ao espaço privado de atuação do internacionalista, os dados revelam que as IES comunitárias foram responsáveis por 
2,50\% das referências, as IES privadas $75 \%$ e as públicas 22,50\%. Nas IES privadas a diferença em pontos percentuais em relação às IES públicas é na ordem de 52,5. É o que vemos no gráfico 7 .

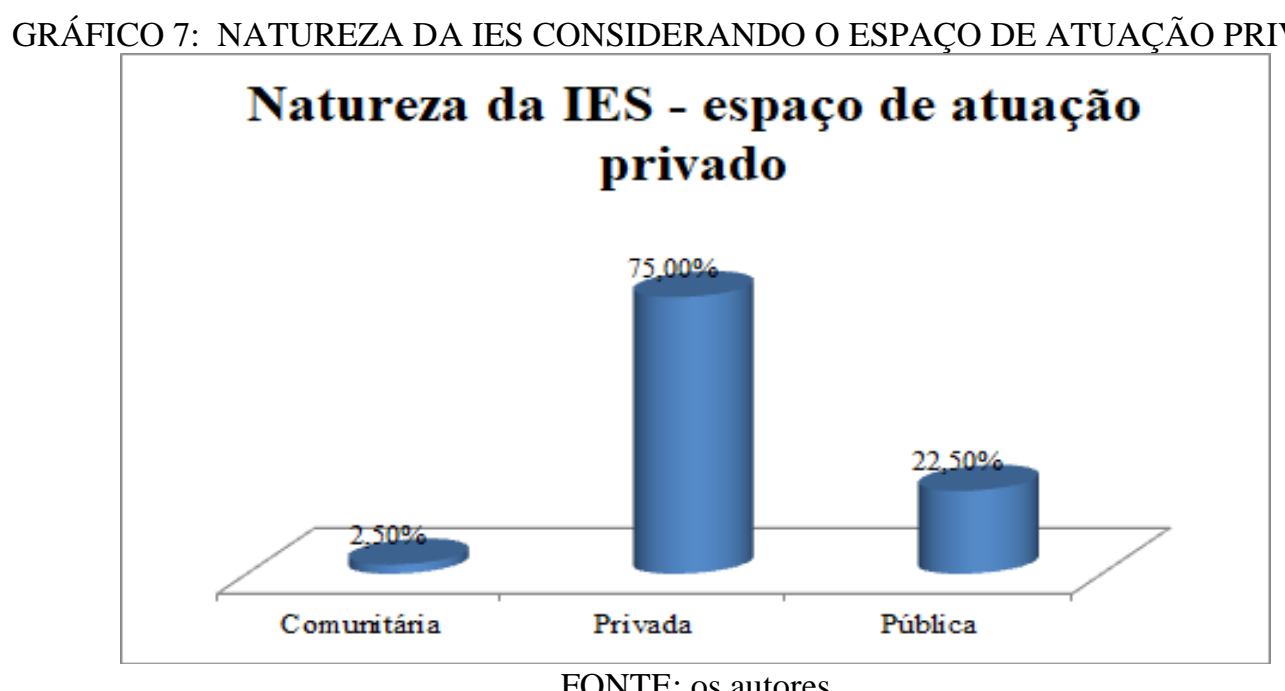

FONTE: os autores

Analisando os dados do gráfico 8, é possível perceber que as IES públicas tiveram 21,15\% do total de referências ao espaço público, enquanto as IES comunitárias tiveram 2,88\% e as IES privadas $75,96 \%$. A diferença em pontos percentuais entre as IES privadas em relação às IES públicas é na ordem de 54,81 .

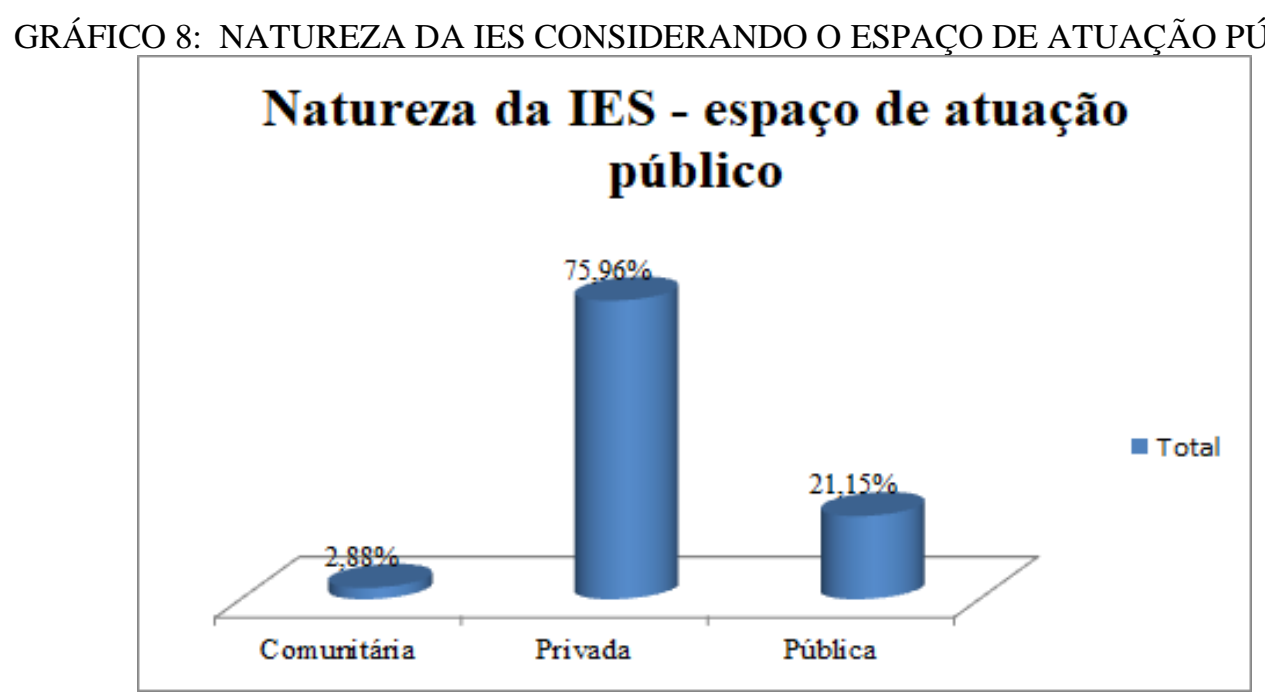

FONTE: os autores

O gráfico 9 traz os dados sobre as referências ao terceiro setor e revela que as IES privadas foram responsáveis por $78,79 \%$ dessas referências, enquanto as IES comunitárias não fizeram 
referências e as IES públicas tiveram um valor de 21,15\%. Quando olhamos para a diferença em pontos percentuais entre as IES públicas e IES privadas observamos o valor na ordem de 57,58.

GRÁFICO 9: NATUREZA DA IES CONSIDERANDO O ESPAÇO DE ATUAÇÃO DO TERCEIRO SETOR

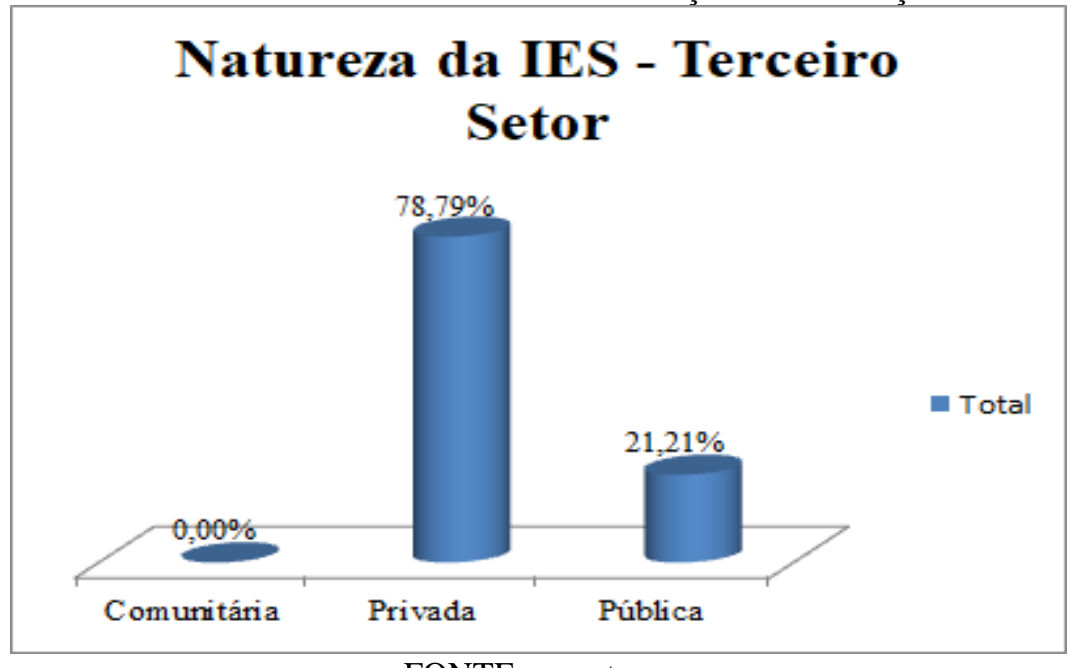

FONTE: os autores

Os dados demonstram que nas referências ao espaço acadêmico, as IES privadas têm 65\%, enquanto as IES públicas possuem $35 \%$ e as IES comunitárias não fazem qualquer referência. A diferença entre as IES públicas e IES privadas em pontos percentuais é no valor de 30. É o que podemos verificar no gráfico 10 .

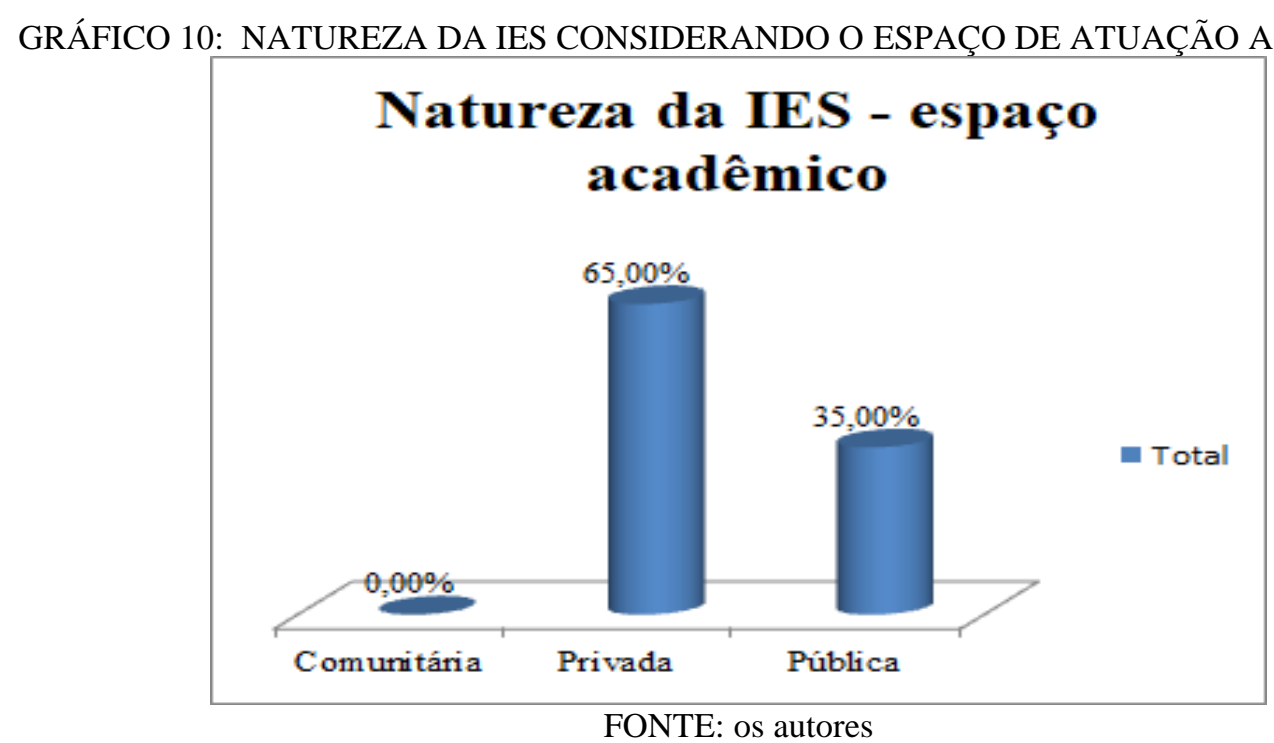

Por último, no gráfico 11 temos os dados sobre as referências às organizações internacionais. As IES privadas foram responsáveis por 69,44\% dessas referências, já as IES comunitárias não 
fizeram nenhuma enquanto as IES públicas tiveram 30,56\%. Quando olhamos para a diferença em pontos percentuais entre as IES públicas e IES privadas observamos o valor na ordem de 38,88. GRÁFICO 11: NATUREZA DA IES CONSIDERANDO O ESPAÇO DE ATUAÇÃO DAS ORGANIZAÇÕES
INTERNACIONAIS

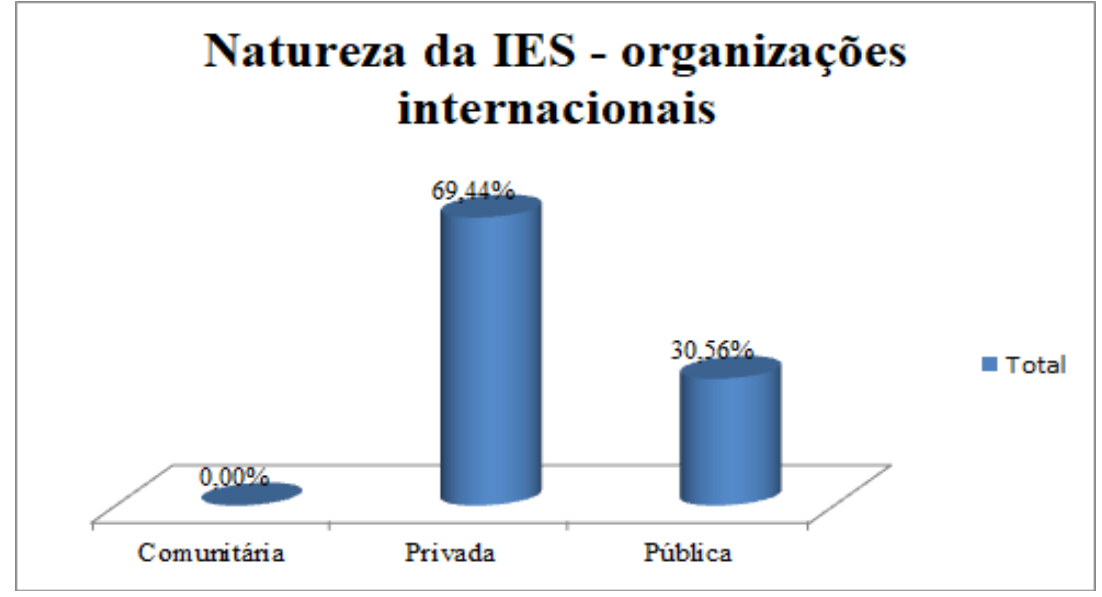

FONTE: os autores

Os dados apresentados no gráfico 12 revelam a distribuição das referências aos espaços de atuação pelas regiões do Brasil. O primeiro apresenta que as referências sobre a atuação no espaço acadêmico tiveram 50\% no Sudeste, enquanto o Centro-Oeste apresentou 25\%, o Nordeste 20\%, o Sul 5\% e o Norte não fez referência sobre a atuação no espaço acadêmico. A diferença em pontos percentuais entre as regiões Sudeste e Centro-Oeste, respectivamente a primeira e a segunda que mais mencionaram, foi de 25 pontos percentuais.

GRÁFICO 12: ATUAÇÃO NO ESPAÇO ACADÊMICO POR REGIÃO

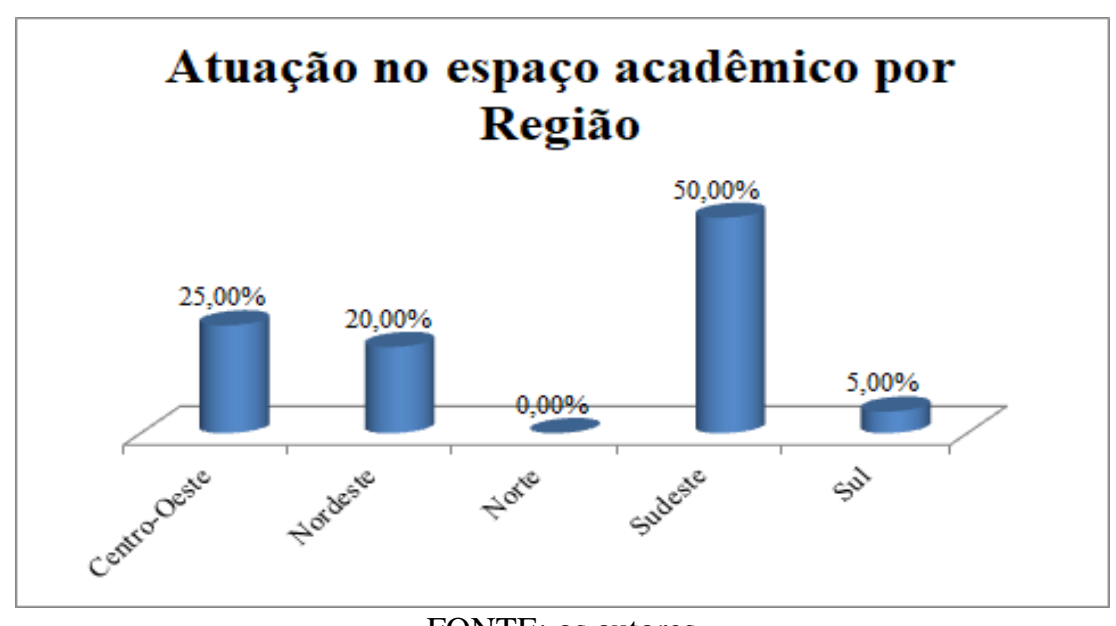

FONTE: os autores 
O gráfico 13 considera as referências sobre a atuação no espaço das organizações internacionais e que estão assim distribuídas: 5,56\% no Norte, o Sul apresentou $16,67 \%$, tanto o Nordeste quanto o Centro-Oeste foram responsáveis por $19,44 \%$ das referências e o Sudeste representou $38,89 \%$. Olhando a diferença em pontos percentuais, entre o Sudeste e o Centro-Oeste atinge o valor de 19.55 pontos, o mesmo ocorre com o e Nordeste.

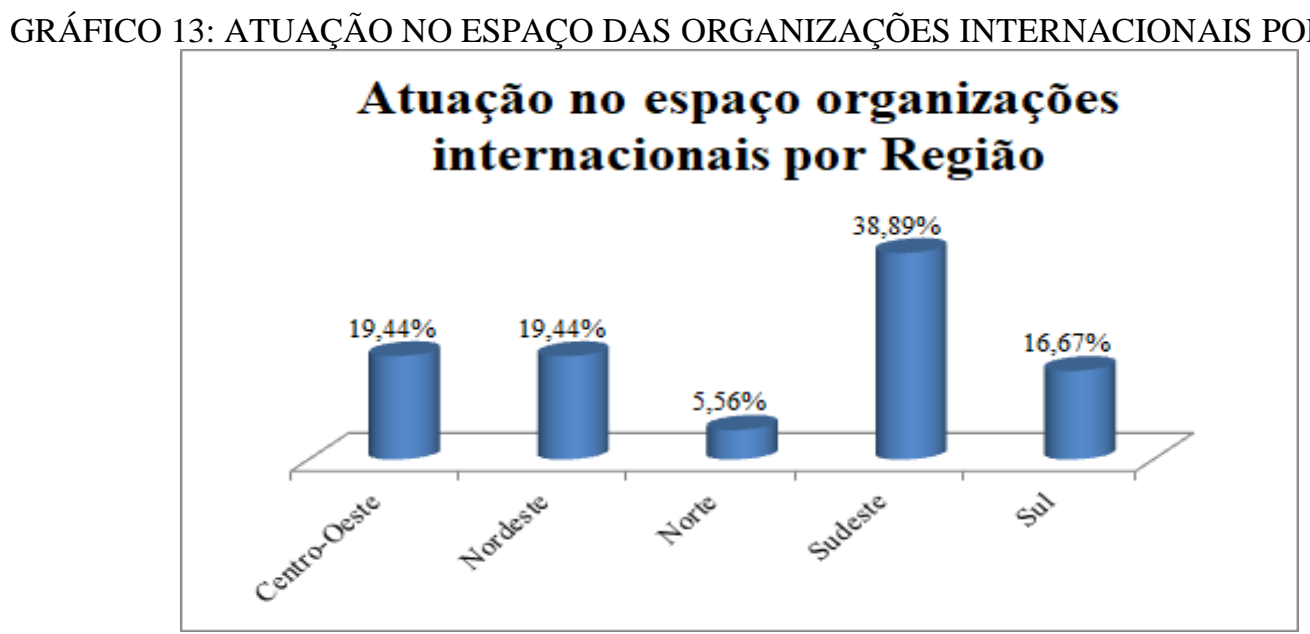

FONTE: os autores

A atuação no espaço do terceiro setor, dados do gráfico 14, foi referenciada pelas regiões com os seguintes valores, 18,18\% pelo Sul, 9,09\% pelo Norte e Centro-Oeste, 12,12\% pelo Nordeste e $51,52 \%$ pelo Sudeste. Observando a diferença em pontos percentuais foi identificada uma distância de 39,4 pontos entre as regiões Sul e Sudeste.

GRÁFICO 14: ATUAÇÃO NO ESPAÇO DO TERCEIRO SETOR POR REGIÃO

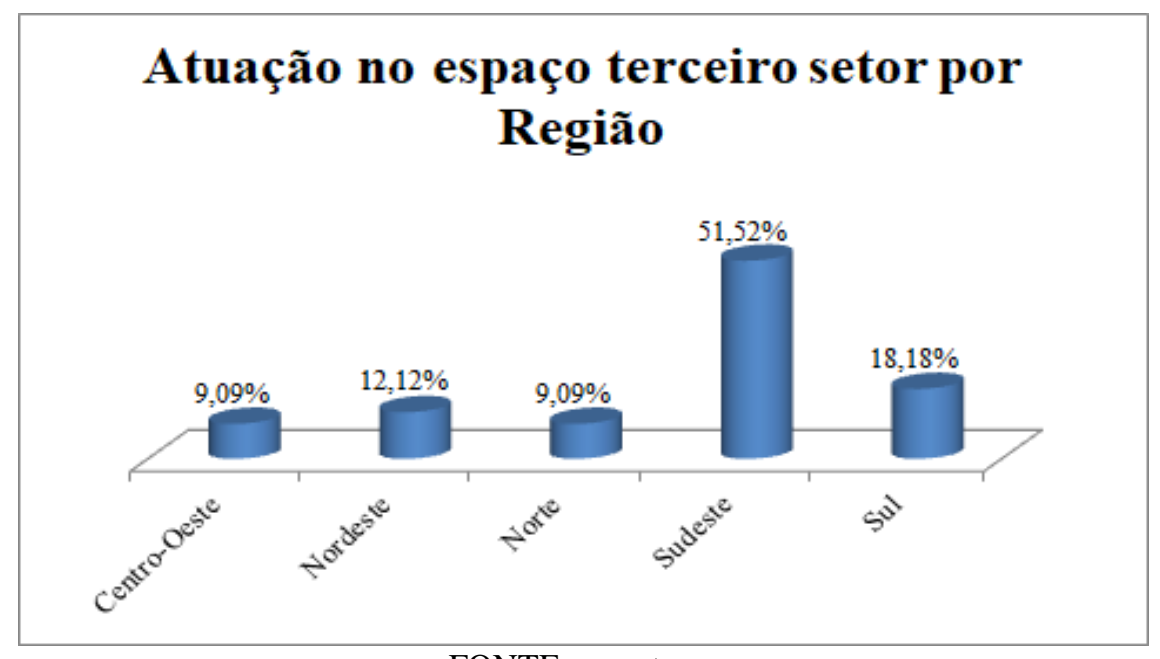

FONTE: os autores 
O gráfico 15 traz as referências sobre a atuação no espaço privado e vemos que 49,04\% destas, estão no Sudeste, o Sul 26,92\%, enquanto o Centro-Oeste e o Nordeste apresentaram cada um, $10,58 \%$, e 2,88\% no Norte. A diferença em pontos percentuais entre o Sudeste e o Sul e foi de 22,12 pontos percentuais.

GRÁFICO 15: ATUAÇÃO NO ESPAÇO PRIVADO POR REGIÃO

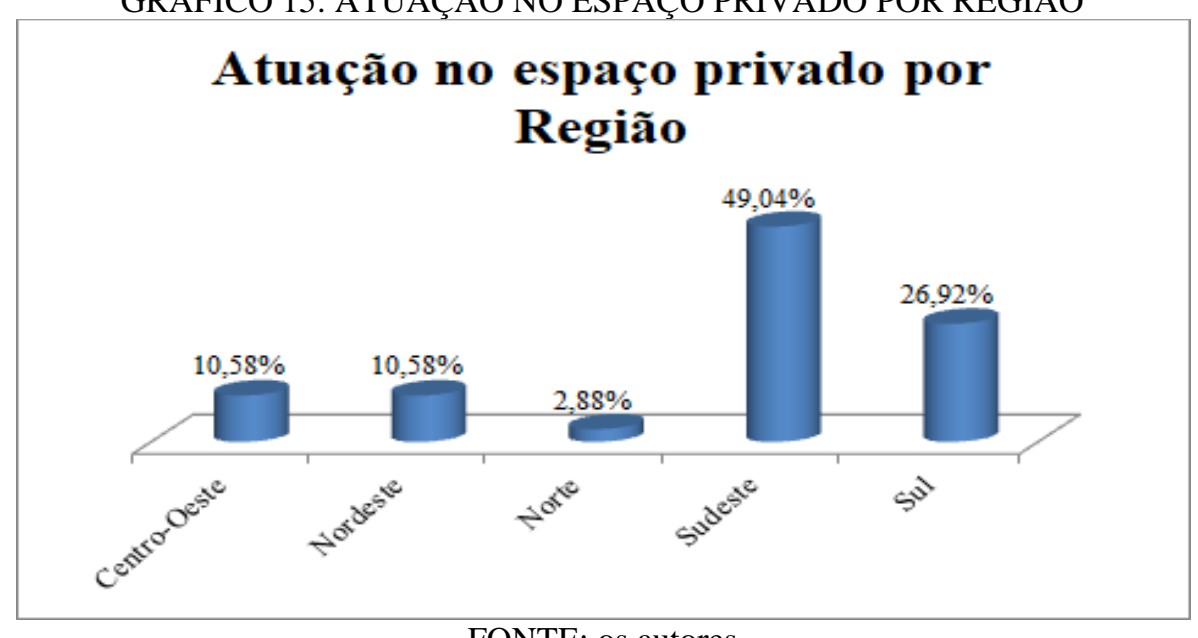

FONTE: os autores

No gráfico 16 foram identificadas as menções ao espaço público sendo a região Norte responsável por $4,12 \%$, o Nordeste e Centro-Oeste por $12,37 \%$, o Sudeste por $48,45 \%$ e o Sul por $22,68 \%$ dessas menções. Em pontos percentuais a distância entre a região Sudeste e Sul, o que mais mencionou e a segunda que mais mencionou respectivamente, é de 22,57.

GRÁFICO 16: ATUAÇÃO NO ESPAÇO PÚBLICO POR REGIÃO

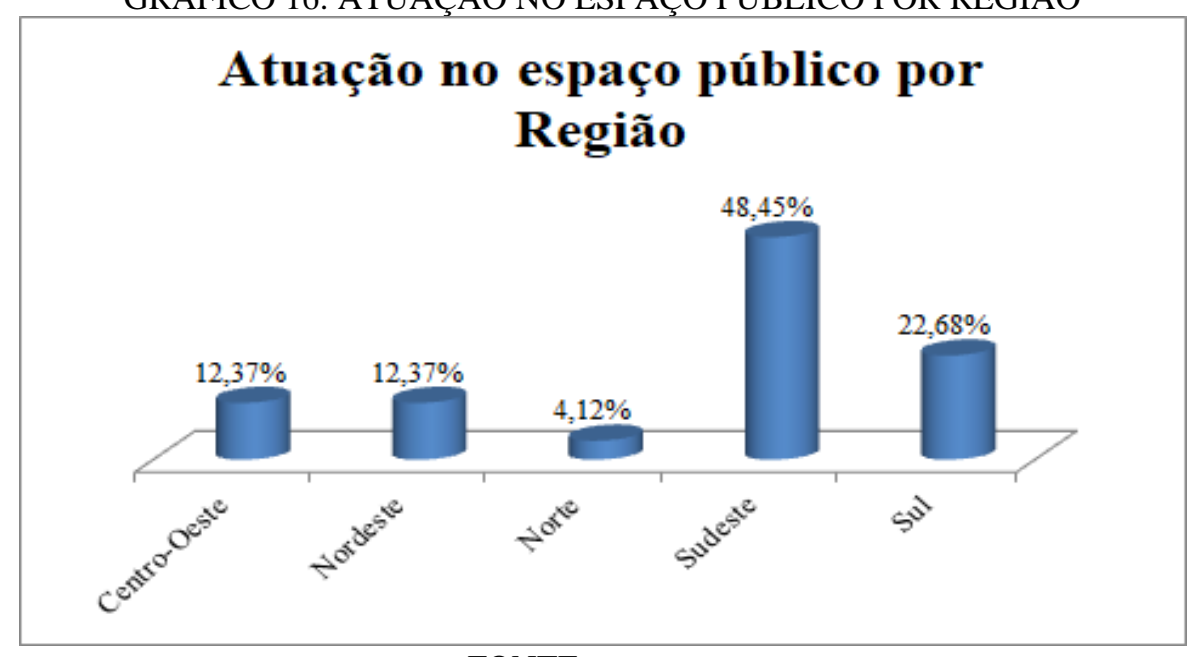

FONTE: os autores 
Nesta seção apresentamos o perfil dos cursos analisados e sua relação com os espaços de atuação (público, privado, terceiro setor, organizações internacionais, acadêmico). Passaremos a desenvolver a análise dos cargos e atividades para o internacionalista na perspectiva dos cursos de relações internacionais.

\subsection{CARGOS E ATIVIDADES DO INTERNACIONALISTA NA PERSPECTIVA DOS CURSOS DE RELAÇÕES INTERNACIONAIS}

Nesta seção a intenção é a de identificar nos sites dos cursos analisados, no espaço reservado às informações sobre o mercado de trabalho, os cargos e as atividades que ali estão mencionados. Estes dados também foram importantes para a seção anterior que adotou uma perspectiva quantitativa e onde pudemos verificar as porcentagens. Aqui nos propomos a uma discussão mais qualitativa, queremos saber quais são os cargos e atividades referenciados e como são referenciados, levantando os pontos que consideramos relevantes e que foram encontrados durante a pesquisa. Ao final sintetizamos as informações em quadros que nos orientarão para uma futura classificação, um dos objetivos do projeto de pesquisa.

Da análise do conteúdo dos sites das instituições analisadas, vemos que as IES públicas tendem a ressaltar a área acadêmica, enquanto as privadas não colocam tanta relevância. As IES tiveram um grande enfoque em destacar as opções na área privada, sempre dando destaque à funções e cargos relacionados a diplomacia corporativa e comércio exterior, segundo o trabalho de Pedro Feliú Ribeiro et. al. (2013), "observa-se que a maior parte dos egressos de RI atuam no setor privado, constituindo-se $45 \%$ de nossa amostra”.

Existe uma preocupação das instituições privadas em demonstrar todas as opções de atuação do egresso no mercado profissional, enquanto que nas instituições públicas as informações são disponibilizadas em caráter informativo, também é possível identificar que as instituições públicas ressaltam a regulação do curso e seu encaixe nas normas governamentais, enquanto que as privadas enfocam a qualidade de seus professores, infraestrutura e do curso da instituição em si, isso acaba por se refletir na busca por atrair alunos através de sites mais organizados, esse é um diferencial encontrado entre os sites das IES privadas e públicas, sendo que as primeiras têm páginas mais completas e detalhadas, em contraponto às segundas possuem muitas vezes sites extremamente desatualizados ou às vezes o curso nem site possui. 
Outra questão relevante que nos trouxe a análise dos sites dos cursos, foi um significativo avanço e consolidação, dentro do espaço privado, da área afeta às relações governamentais/institucionais como atividade desenvolvida pelo internacionalista.

\section{QUADRO 1- CARGOS E ATIVIDADES IES PÚBLICAS}

\begin{tabular}{|c|c|c|}
\hline IES Públicas & Cargos & Atividades \\
\hline $\begin{array}{l}\text { Atividades comuns } \\
\text { aos espaços }\end{array}$ & $\begin{array}{l}\begin{array}{l}\text { Analista de } \\
\text { internacional, }\end{array} \\
\text { internacional. }\end{array}$ & $\begin{array}{l}\text { Consultoria; Entender e lidar com desafios políticos e } \\
\text { econômicos internacionais; Analisar e interpretar o } \\
\text { contexto internacional; Assessorar e fazer consultoria } \\
\text { internacionais. }\end{array}$ \\
\hline Pública & Diplomata. & Diplomacia. \\
\hline Privada (clássica) & $\begin{array}{l}\text { Negociador; Assessor e Consultor de } \\
\text { Exportação/Importação; Analista } \\
\text { financeiro. }\end{array}$ & $\begin{array}{l}\text { Assessorar e fazer consultoria em processos de exportação } \\
\text { e importação; Negociar internacionalmente. }\end{array}$ \\
\hline Privada (RelGov) & $\begin{array}{l}\text { Comunicador; Analista Político, } \\
\text { Assessor governamental e } \\
\text { parlamentar. }\end{array}$ & $\begin{array}{l}\text { Diplomacia empresarial; Comunicação/Imprensa; } \\
\text { Assessorar órgãos públicos e políticos. }\end{array}$ \\
\hline Acadêmica & Pesquisador; Professor. & Fazer pesquisas; Ensinar - Dar aulas. \\
\hline
\end{tabular}

FONTE: os autores

Ao olharmos para a tabela acima identificamos as atividades e cargos referenciados nos sites das IES Públicas, pegando primeiramente os cargos e atividades que classificamos como comuns aos espaços público, privado, acadêmico, organizações internacionais e terceiro setor, encontramos referências a cargos de analista de RI; assessor internacional; consultor internacional;. Em seguida constam as atividades como consultoria; entender e lidar com desafios políticos e econômicos internacionais; analisar e interpretar o contexto internacional; assessorar e fazer consultoria internacionais. 
Passando para as menções a área pública, as IES públicas se limitam a descrever o cargo e atividade como, respectivamente, diplomata e diplomacia

A área privada foi separada em duas, a primeira é a que denominamos como clássica, que cita os cargos de negociador; assessor e consultor de exportação/importação; analista financeiro. As atividades referenciadas na clássica foram as de assessorar e fazer consultoria em processos de exportação e importação; negociar internacionalmente. A segunda foi a de Relações Governamentais, os cargos mencionados foram comunicador; analista político; assessor governamental e parlamentar. Olhando para as atividades referenciadas encontramos a diplomacia empresarial; comunicação/imprensa; assessorar órgãos públicos e políticos. Por último olhamos para as referências a área acadêmica, as IES públicas citam os cargos de pesquisador e professor. As atividades desenvolvidas são fazer pesquisas e ensinar - dar aulas.

QUADRO 2- CARGOS E ATIVIDADES IES PRIVADAS

\begin{tabular}{|c|c|c|}
\hline $\begin{array}{l}\text { IES } \\
\text { Privadas }\end{array}$ & Cargos & Atividades \\
\hline $\begin{array}{l}\text { Atividades } \\
\text { comuns aos } \\
\text { espaços }\end{array}$ & $\begin{array}{l}\text { Analista de RI; Assessor e consultor } \\
\text { privado e público; Assessor internacional. }\end{array}$ & $\begin{array}{l}\text { Elaborar e avaliar informações sobre a } \\
\text { conjuntura/cenário/contexto internacional, formulação de } \\
\text { cenários, projeções internacionais; Análise do sistema } \\
\text { mundo; Consultoria técnica; Assessoria internacional. }\end{array}$ \\
\hline Pública & Diplomata; Oficial de Chancelaria. & $\begin{array}{l}\text { Diplomacia; Paradiplomacia; Integrar comissões e cortes } \\
\text { internacionais; participar da criação de acordos bilaterais } \\
\text { ou multinacionais. Integrar comissões em agências de } \\
\text { cooperação internacional; Auxiliar diplomatas no trabalho } \\
\text { interno e externo. }\end{array}$ \\
\hline Privada & $\begin{array}{l}\text { Negociador; Assessor e } \begin{array}{l}\text { Consultor de } \\
\text { Exportação/Importação. } \\
\text { Internacionalização; }\end{array} \text { Mercadólogo } \\
\text { Internacional; Planejador de Negócios; } \\
\text { Analista de políticas comerciais; Assessor e } \\
\text { consultor de comércio internacional; } \\
\text { Analista de riscos de mercado. }\end{array}$ & $\begin{array}{l}\text { Analisar negócios internacionais; Analisar as finanças; } \\
\text { Internacionalizar empresas; Assessorar e fazer consultoria } \\
\text { em processos de exportação e importação; Negociar } \\
\text { internacionalmente; Elaborar planos de negócios; } \\
\text { Regulamentar serviços internacionais; análise de riscos de } \\
\text { mercado em bancos internacionais e nacionais; Avaliar as } \\
\text { possibilidades de negócio e investimento no exterior; } \\
\text { Gerenciar empresas. }\end{array}$ \\
\hline $\begin{array}{l}\text { Privada } \\
\text { (relgov) }\end{array}$ & $\begin{array}{l}\text { Assessor e consultor político e econômico; } \\
\text { Assessor de comunicação; Analista de } \\
\text { Cenários de Risco; Diplomata Corporativo; } \\
\text { Planejador; profissional de Relações } \\
\text { Governamentais. }\end{array}$ & $\begin{array}{l}\text { Assessorar politicamente; Assessorar a comunicação, } \\
\text { Diplomacia Corporativa; formular e implementar } \\
\text { estratégias de relacionamento com stakeholders; fazer } \\
\text { marketing internacional. Prestar assessoria e consultoria } \\
\text { para municípios e governos estaduais; Fazer relações } \\
\text { governamentais; Consultoria de risco político; Relações }\end{array}$ \\
\hline
\end{tabular}




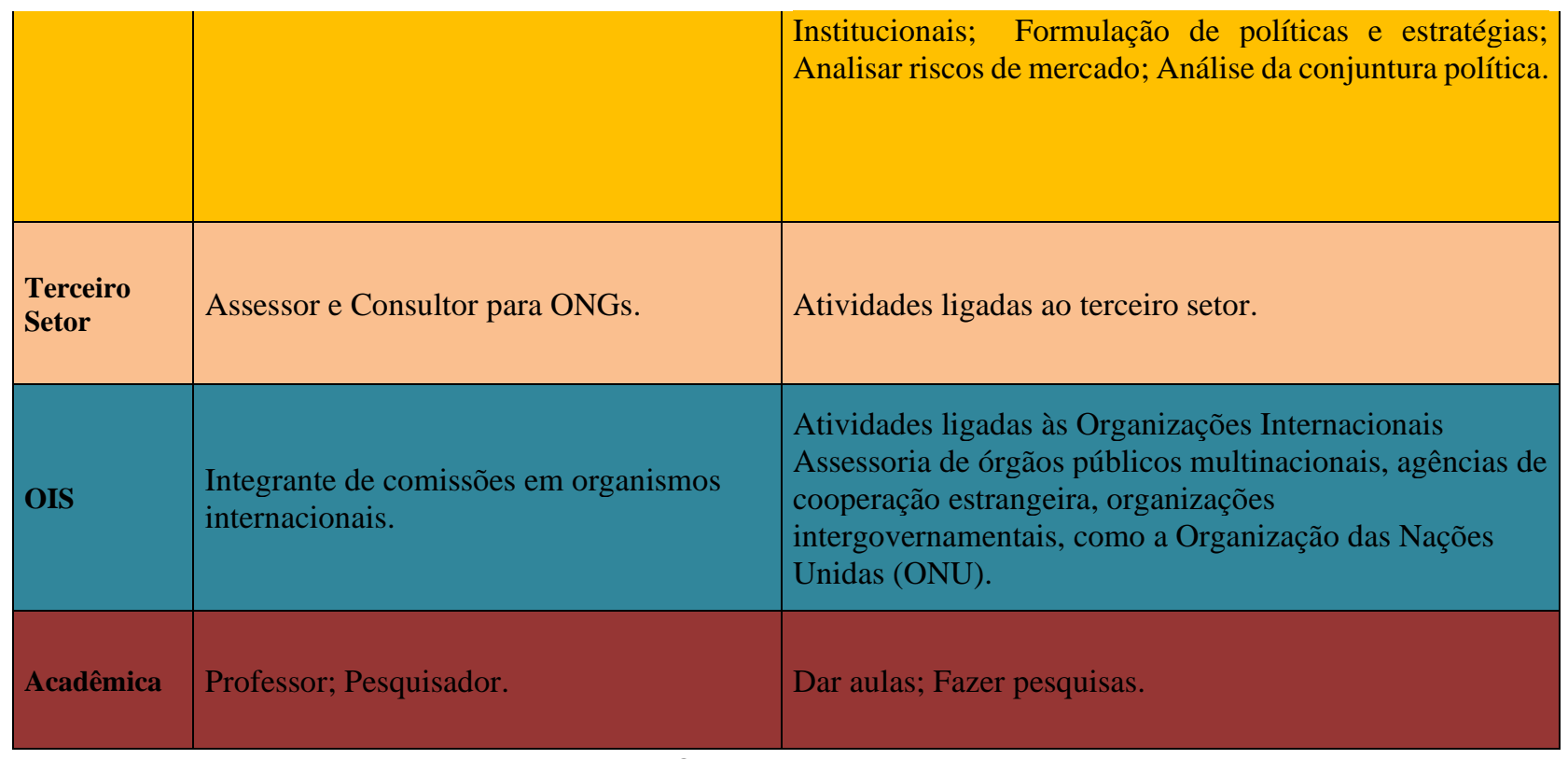

FONTE: os autores

Observando a tabela acima, que trata dos cargos e atividades referenciados pelas IES privadas, começando pelas atividades e cargos comuns aos espaços, os cargos descritos nessa categoria foram analista de RI; assessor e consultor privado e público; assessor internacional. As atividades desenvolvidas citadas foram elaborar e avaliar informações sobre a conjuntura/cenário/contexto internacional; formulação de cenários; projeções internacionais; análise do sistema mundo; consultoria técnica; assessoria internacional.

Olhando para as menções à área pública, os cargos mencionados foram diplomata e oficial de chancelaria e as atividades desenvolvidas foram diplomacia; paradiplomacia; integrar comissões e cortes internacionais; participar da criação de acordos bilaterais ou multinacionais. integrar comissões em agências de cooperação internacional; auxiliar diplomatas no trabalho interno e externo.

Assim como na tabela das IES públicas a área privada foi separada em duas, a clássica que mencionou os cargos de negociador; assessor e consultor de exportação/importação; agente de internacionalização; mercadólogo internacional; planejador de negócios; analista de políticas comerciais; assessor e consultor de comércio internacional; analista de riscos de mercado. As atividades mencionadas foram analisar negócios internacionais; analisar as finanças; internacionalizar empresas; assessorar e fazer consultoria em processos de exportação e importação; negociar internacionalmente; elaborar planos de negócios; regulamentar serviços internacionais; análise de riscos de mercado em bancos internacionais e nacionais; avaliar as possibilidades de negócio e investimento no exterior; gerenciar empresas. Já a relações governamentais trouxe menções aos cargos de assessor e consultor político e econômico; assessor de comunicação; analista de 
cenários de risco; diplomata corporativo; planejador; profissional de relações governamentais. Trouxe também menções as atividades de assessorar politicamente; assessorar a comunicação, diplomacia corporativa; formular e implementar estratégias de relacionamento com stakeholders; fazer marketing internacional; prestar assessoria e consultoria para municípios e governos estaduais; fazer relações governamentais; consultoria de risco político; formulação de políticas e estratégias; analisar riscos de mercado; análise da conjuntura política.

As menções aos cargos e atividades do terceiro setor foram somente, respectivamente, assessor e consultor para ONGs e atividades ligadas ao terceiro setor.

Olhando para as citações sobre cargos e atividades nas Organizações Internacionais, foram identificados o cargo de integrante de comissões em organismos internacionais com as atividades ligadas às OIS; Assessoria de órgãos públicos multinacionais, agências de cooperação estrangeira, organizações intergovernamentais, como a Organização das Nações Unidas (ONU).

Por último foram identificadas para a área acadêmica, os cargos de professor e pesquisador e as atividades de fazer pesquisa e dar aulas.

Ao compararmos as duas tabelas acima, pudemos identificar que não houve menção nas IES públicas sobre cargos e atividades das áreas de Terceiro Setor e Organizações Internacionais, continuando nas IES públicas as menções a cargos e atividades da área pública ficaram restritas a diplomata e diplomacia, enquanto as IES privadas tiveram menções mais variadas. Porém ambas mencionaram os mesmos cargos e atividades na área acadêmica.

\section{CONSIDERAÇÕES FINAIS}

O presente trabalho avaliou os cursos de referência (nota 5) no cenário educacional brasileiro na área de relações internacionais. As análises das propostas de ensino e das apresentações das informações do curso nas diferentes instituições em todo o Brasil revelaram algumas diferenças existentes na sociedade brasileira, assim como tendências sociais. Foi possível observar a maior concentração de instituições de ensino nas regiões mais prósperas do país assim como uma maior estruturação e preocupação com o egresso, e sua percepção de abrangência do mercado de trabalho. Visualizamos o ensino privado focando na inserção do egresso no meio privado e o ensino público destacando a importância do meio acadêmico, onde predominam-se as pesquisas acadêmica no território nacional. 
Os dados apresentados no 2.1 demonstram que as IES com conceito de curso 5 foram em sua maioria de modalidade presencial, de natureza privada e localizados nos estados de Minas Gerais, Rio de Janeiro, Rio Grande do Sul e São Paulo, portanto houve proeminência da região sudeste. Levando tais dados em conta é importante ressaltar que houve dominância das IES privadas e da região sudeste quando os dados eram cruzados com as demais IES e regiões, mas é importante ressaltar que isso não pode ser entendido como um dado de qualidade "público x privado" e tampouco como superioridade da região sudeste.

A diferença das referências entre as IES públicas e privadas foram maiores nos espaços privado, público e terceiro setor, entretanto quando se olha para as citações dos espaços acadêmicos e nas organizações internacionais esse distanciamento diminui. O mesmo pode ser dito quanto aos dados por região, o Sudeste se mantém com que mais cita, porém dependendo do espaço de atuação os segundo e terceiro que mais citam variam entre as demais regiões, algumas vezes até empatando

Quando observada as citações sobre os espaços de atuação, discriminando a natureza das IES, foi possível identificar uma pequena diferença entre os espaços público e privado, em comparação com as citações dos demais espaços.

Tendo em vista os cargos e atividades do internacionalista na perspectiva dos cursos de relações internacionais, é possível identificar semelhanças entre as citações feitas pelas IES privadas e públicas. Também é importante apontar que existe uma maior citação de cargos e atividades pelos sites das IES privadas, tanto no espaço de atuação público quanto privado. As IES públicas não mencionaram os cargos e atividades dos espaços de atuação do Terceiro Setor e Organizações Internacionais.

Um dado interessante que foi identificado no decorrer do trabalho foram as citações a Relações Governamentais por treze IES, nove privadas, três públicas e uma comunitária, dando a impressão de que é um setor que está se estabelecendo como uma das atividades que o Internacionalista formado é capaz de executar com as habilidades e competências desenvolvidas pelas IES.

Os dados coletados reforçam a importância de futuras pesquisas acompanhando as mudanças de mercado, assim como as adaptações dos cursos de relações internacionais no Brasil. Se faz necessário verificar se os mesmos possuem a preocupação de formar profissionais que atendam as demandas sociais e mercadológicas de um internacionalista e que esteja o mesmo se sinta apto a resolver os problemas atuais, contribuindo com o avanço do meio em que se encontra inserido. 
A pesquisa irá continuar, os cursos com conceito de curso três e quatro serão os próximos a serem analisados, assim expandindo o universo e possibilitando uma visão mais ampla e clara da situação do mercado de trabalho segundo a visão das instituições de ensino superior. Assim como analisaremos o mercado de trabalho para o internacionalista na perspectiva das vagas de emprego e estágio.

\section{REFERÊNCIAS}

BARDIN, L. Análise de Conteúdo. São Paulo, Almedina, 2011

BORGES, Gustavo de Azevedo; LIMA, Rhennan Lazaro de Paulo; LINA, Laís Machado; VAZ, Débora Ribeiro. Mercado de trabalho, empregabilidade e suas variações. (2019) Disponível em: https://repositorio.ifgoiano.edu.br/bitstream/prefix/472/1/MERCADO\%20DE\%20TRABALHO\%2 C\%20EMPREGABILIDADE\%20E\%20SUAS\%20VARIA\%C3\%87\%C3\%95ES.pdf. Acesso em 02/02/2019.

CENTRO UNIVERSITÁRIO BELAS ARTES DE SÃO PAULO. Bacharelado em Relações Internacionais. Disponível em: https://novo.belasartes.br/graduacao/relacoes-internacionais/. Acesso em: 10/06/2020

CENTRO UNIVERSITÁRIO DE BELO HORIZONTE. Bacharelado em Relações Internacionais. Disponível em: https://www.unibh.br/cursos/relacoesinternacionais/?place_id=1127\&shift=Manh\%C3\%A3+e+Noite\&ingress=vestibular\#. Acesso em: $14 / 06 / 2020$.

CENTRO UNIVERSITÁRIO DE BRASÍLIA. Bacharelado em Relações Internacionais. Disponível em: https://www.uniceub.br/pdp/Graduacao/Ciencias-Sociais-Aplicadas/relacoesinternacionais. Acesso em: 14/06/2020.

CENTRO UNIVERSITÁRIO DO INSTITUTO DE EDUCAÇÃO SUPERIOR DE BRASÍLIA. Bacharelado em Relações Internacionais. Disponível em: https://www.iesb.br/graduacao/curso/relacoes-internacionais. Acesso em 12/06/2020.

CENTRO UNIVERSITÁRIO ESTÁCIO DA BAHIA. Bacharelado em Relações Internacionais. Disponível em: https://portal.estacio.br/graduacao/rela\%C3\%A7\%C3\%B5es-internacionais. Acesso em: 10/06/2020.

CENTRO UNIVERSITÁRIO IBMEC. Bacharelado em Relações Internacionais. Disponível em: https://www.ibmec.br/rj/cursos/graduacao/gestao-e-negocios/relacoes-internacionais. Acesso em: $12 / 06 / 2020$. 
CENTRO UNIVERSITÁRIO INTERNACIONAL. Bacharelado em Relações Internacionais. Disponível em: https://www.uninter.com/graduacao-ead/curso-relacoes-internacionais/. Acesso em: $15 / 06 / 2020$.

CENTRO UNIVERSITÁRIO RITTER DOS REIS. Bacharelado em Relações Internacionais. Disponível em: https://www.uniritter.edu.br/graduacao/relacoes-internacionais. Acesso em: $15 / 06 / 2020$.

CENTRO UNIVERSITÁRIO SENAC. Bacharelado em Relações Internacionais. Disponível em: http://www.sp.senac.br/jsp/default.jsp?template=971.dwt\&amp;testeira=980\&amp;unit=NONE \&amp;type=NONE\&amp;speciality=617\&amp;theme_name $=$ Rela\%E7\%F5es\%20Internacionais \& amp;sub=2. Acesso em: 12/06/2020

ESCOLA SUPERIOR DE PROPAGANDA E MARKETING. Bacharelado em Relações Internacionais. Disponível em: https://www.espm.br/graduacao/sao/sao-relacoes-internacionais/. Acesso em: 10/06/2020.

ESCOLA SUPERIOR DE PROPAGANDA E MARKETING DE PORTO ALEGRE. Bacharelado em Relações Internacionais. Disponível em: https://www.espm.br/graduacao/sul/sul-relacoesinternacionais/. Acesso em: 10/06/2020.

FACULDADE DAMAS DA INSTRUÇÃO CRISTÃ. Bacharelado em Relações Internacionais. Disponível em: https:/www.faculdadedamas.edu.br/graduacao/relacoes-internacionais/. Acesso em: $10 / 06 / 2020$

FACULDADE DE CAMPINAS. Bacharelado em Relações Internacionais. Disponível em: https://www.facamp.com.br/cursos/humanas/relacoes-internacionais/. Acesso em: 10/06/2020.

FACULDADE IBMEC. Bacharelado em Relações Internacionais. Disponível em: https://www.ibmec.br/mg/cursos/graduacao/gestao-e-negocios/relacoes-internacionais. Acesso em $12 / 06 / 2020$.

FACULDADES INTEGRADAS RIO BRANCO GRANJA VIANNA. Bacharelado em Relações Internacionais. Disponível em: Site: http://www.riobrancofac.edu.br/Site/cursos/graduacao/relacoes-internacionais/relacoesinternacionais.aspx. Acesso em: 12/06/2020.

FGV / ESCOLA DE RELAÇÕES INTERNACIONAIS. Bacharelado em Relações Internacionais. Disponível em: https://vestibular.fgv.br/cursos/sao-paulo/relacoes-internacionais. Acesso em: 10/06/2020.

FUNDAÇÃO UNIVERSIDADE FEDERAL DO ABC. Bacharelado em Relações Internacionais. Disponível em: http://prograd.ufabc.edu.br/cursos/bri. Acesso em: 13/06/2020.

LEMOS, Ana Helena da Costa; RODRIGUEZ, Daniel Arbaiza. (2008). Empregabilidade: conquista da autonomia profissional ou nova forma de submissão? Anais do Encontro Nacional da Associação Nacional de Pós-Graduação e Pesquisa em Administração. Belo Horizonte, MG, Brasil, 32. 
LEMOS, Ana Heloísa da Costa; PINTO, Mário Couto Soares. Empregabilidade dos administradores: quais os perfis profissionais demandados pelas empresas? Cadernos EBAPE.BR, v. 6, no 4, dez. 2008, p. 1-15.

MINISTÉRIO DA EDUCAÇÃO. Cadastro e-MEC, 2020. Disponível em: http://emec.mec.gov.br/. Acesso em: 14/05/2020.

PONTIFÍCIA UNIVERSIDADE CATÓLICA DE MINAS GERAIS. Bacharelado em Relações Internacionais. Disponível em: https://www.pucminas.br/unidade/coracaoeucaristico/ensino/graduacao/Paginas/RelacoesInternacionais.aspx?moda=2\&amp;curso=240\&amp;local=ab23480c-5f60-4752-b9901ac1cf9b8cf5. Acesso em: 12/06/2020.

PONTIFÍCIA UNIVERSIDADE CATÓLICA DE SÃO PAULO. Bacharelado em Relações Internacionais. Disponível em: https://www.pucsp.br/graduacao/relacoes-internacionais. Acesso em: $12 / 06 / 2020$.

PONTIFÍCIA UNIVERSIDADE CATÓLICA DO RIO DE JANEIRO. Bacharelado em Relações Internacionais. Disponível em: https://www.puc-rio.br/ensinopesq/ccg/rel_internacionais.html. Acesso em: 12/06/2020.

RIBEIRO, Pedro Feliú; KATO, Mariana; RAINER, Gary. Mercado de Trabalho e Relações Internacionais no Brasil: um estudo exploratório. Boletim Meridiano 47, vol. 14, n. 135, jan-fev. 2015, p. 10-18.

UNIVERSIDADE CATÓLICA DE PETRÓPOLIS. Bacharelado em Relações Internacionais. Disponível em: http://www.ucp.br/index.php?option=com_content\&amp;view=article\&amp;id=281 :sobre-o-cursori\&amp;catid=145\&amp;Itemid=1107\&amp;lang=pt. Acesso em: 12/06/2020.

UNIVERSIDADE DA AMAZÔNIA. Bacharelado em Relações Internacionais. Disponível em: https://vestibular.unama.br/PS_Unama/curso/79/1267/1/relacoes-internacionais/Belém-PA. Acesso em: 14/06/2020.

UNIVERSIDADE DE RIBEIRÃO PRETO. Bacharelado em Relações Internacionais. Disponível em: https://www.unaerp.br/cursos/relacoes-internacionais. Acesso em: 14/06/2020.

UNIVERSIDADE DE SANTA CRUZ DO SUL. Bacharelado em Relações Internacionais. Disponível em: https://www.unisc.br/pt/cursos/todos-os-cursos/graduacao/bacharelado/relacoesinternacionais. Acesso em: 15/06/2020.

UNIVERSIDADE DO RIO DOS SINOS. Bacharelado em Relações Internacionais. Disponível em: https://www.unisinos.br/graduacao/relacoes-internacionais/sao-leopoldo. Acesso em: $15 / 06 / 2020$ 
UNIVERSIDADE DO VALE DO ITAJAÍ. Bacharelado em Relações Internacionais. Disponível em: https://www.univali.br/graduacao/relacoes-internacionais-itajai/Paginas/default.aspx. Acesso em: 16/06/2020.

UNIVERSIDADE FEDERAL DE GOIÁS. Bacharelado em Relações Internacionais. Disponível em: https://prograd.ufg.br/p/8989-relacoes-internacionais-goiania. Acesso em: 13/06/2020.

UNIVERSIDADE FEDERAL DE RORAIMA. Bacharelado em Relações Internacionais. Disponível em: http://ufrr.br/relacoesinternacionais/index.php/component/content/article?id=45. Acesso em: 13/06/2020.

UNIVERSIDADE FEDERAL DE SANTA CATARINA. Bacharelado em Relações Internacionais. Disponível em: https://ri.ufsc.br/sobre-o-curso/\#ingresso. Acesso em: 14/06/2020.

UNIVERSIDADE FEDERAL DE SÃO PAULO. Bacharelado em Relações Internacionais. Disponível em: https://www.unifesp.br/reitoria/prograd/pro-reitoria-degraduacao/cursos/informacoes-sobre-os-cursos. Acesso em: 14/06/2020.

UNIVERSIDADE FEDERAL DE SERGIPE. Bacharelado em Relações Internacionais. Disponível em: http://ccsa.ufs.br/pagina/20147-departamento-de-relacoes-internacionais. Acesso em: $14 / 06 / 2020$.

UNIVERSIDADE FEDERAL DE UBERLÂNDIA. Bacharelado em Relações Internacionais. Disponível em: http://www.ie.ufu.br/graduacao/relacoesinternacionais. Acesso em: 14/06/2020.

UNIVERSIDADE FEDERAL DO PAMPA. Bacharelado em Relações Internacionais. Disponível em: http://cursos.unipampa.edu.br/cursos/relacoesinternacionais/informacoes/. Acesso em: $15 / 06 / 2020$.

UNIVERSIDADE FEDERAL FLUMINENSE. Bacharelado em Relações Internacionais. Disponível em: http://www.uff.br/?q=curso/relacoes-internacionais/108648/bacharelado/niteroi. Acesso em: 13/06/2020.

UNIVERSIDADE LA SALLE. Bacharelado em Relações Internacionais. Disponível em: https://www.unilasalle.edu.br/vestibular/canoas/curso/graduacao-em-relacoes-internacionais-1.

Acesso em: 15/06/2020.

UNIVERSIDADE SALVADOR. Bacharelado em Relações Internacionais. Disponível em: https://www.unifacs.br/graduacao-bacharelado/relacoes-internacionais/. Acesso em: 14/06/2020.

UNIVERSIDADE VEIGA DE ALMEIDA. Bacharelado em Relações Internacionais. Disponível em: https://www.uva.br/content/relacoes-internacionais. Acesso em: 16/06/2020.

WYDEN EDUCACIONAL. Bacharelado em Relações Internacionais. Disponível em: https://www.eadwyden.com.br/curso/relacoes-internacionais/. Acesso em: 16/06/2020.

ZAGO, Vanessa Bernardil; SILVEIRA, José Renato Ferraz da. O Mercado de trabalho do profissional de Relações Internacionais: oportunidades e desafios. (2018). Disponível em: 
https://docplayer.com.br/2320465-O-mercado-de-trabalho-do-profissional-de-relacoesinternacionais-oportunidades-e-desafios-resumo.html. Acesso em: 02/02/2020. 